eISSN: 2659-6482

DOI: https://doi.org/10.14201/pmrt.20615

\title{
¿MOZART ERA UN MUTANTE? \\ Propuestas Didácticas sobre la Música Preexistente en el Cine de Superhéroes
}

\section{Was Mozart a mutant? \\ Didactic Proposals on Pre-Existing Music in Superhero Movies}

\author{
Vicente GALBIS LÓPEZ \\ Universitat de València \\ vicente.galbis@uv.es
}

RESUMEN: Con el inicio del siglo XXI se produjo el comienzo de una edad dorada para el cine de superhéroes; especialmente, en las películas basadas en cómics de la editorial Marvel. Su éxito se debe, sobre todo, a la adaptación al cine del concepto de "universo compartido», lo que permite mostrar personajes y situaciones interrelacionadas. Ello ofrece la opción de conectar con diversas promociones de alumnos, puesto que se trata de personajes presentes en los cines durante las últimas dos décadas. Como muestra de ello, en esta propuesta se incluirán fragmentos de dos películas distantes en el tiempo: X-Men 2 (2003) y Thor: Ragnarok (2017). La popularidad creciente de estos filmes se ve intensificada con un abundante merchandasing y la extensión de este universo a otros audiovisuales de creciente éxito, como las series de televisión. Conectar la cultura audiovisual de los discentes con el entorno académico resulta un elemento motivador $\mathrm{y}$ estos audiovisuales forman parte del entorno cotidiano de un alumnado que, además, es bastante diverso. De hecho, y tal como sucede en los cómics, el consumo de estas películas resulta más evidente en etapas como la enseñanza secundaria, el bachillerato y, sobre todo, la enseñanza superior. La propuesta presentada se dirige al último nivel educativo citado.

Las aplicaciones didácticas se van a centrar en la música preexistente utilizada en este tipo de cine. Esto no supone un rechazo a la música de creación original, pero la menor cantidad de música preexistente permite 
VICENTE GALBIS LÓPEZ

¿MOZART ERA UN MUTANTE? PROPUESTAS DIDÁCTICAS SOBRE LA MÚSICA PREEXISTENTE EN EL CINE DE SUPERHÉROES

un mayor acotamiento de la propuesta $y$, especialmente, un significativo recorrido didáctico gracias a las características y connotaciones que trae consigo esa música. La versatilidad de estos audiovisuales y su pertinencia para un aprendizaje significativo se constata al proponer ejemplos que incluyen tanto música de concierto (Mozart) como popular urbana (Led Zeppelin). Por último, la música preexistente permite unos recorridos didácticos alternativos y unas interesantes opciones de aprendizaje transversal.

Palabras clave: didáctica de la música; cine de superhéroes; didáctica a través de los audiovisuales; películas Marvel; música de concierto; música rock.

ABSTRACT: With the arrival of the 21st century, a Golden age began for the superhero movies, especially, in the films based on Marvel comics. Its success is due, above all, to the adaptation to the cinema of the concept of «shared universe», which allows to show interrelated characters and situations. This allows connecting with students of different ages, because we are talking about film characters from the last two decades. In evidence of this, the proposal will include fragments of two films that are distant in time: X2 (2003) and Thor: Ragnarok (2017). The growing popularity of these films is intensified by an abundant merchandising and the extension of this universe to other audio-visuals of growing success, such as television series. It is very motivating to establish links between the academic pretensions and the audio-visual culture of the students. In addition, these audio-visuals are part of their diverse daily environment. In fact, as it happens with comics, the consumption of these films is more evident in stages such as secondary education, high school and, above all, higher education. The proposal presented is directed to the last mentioned educational level.

The didactic applications will focus on the pre-existing music used in this kind of movies. This does not imply a rejection to the music of original creation, but the smaller quantity of pre-existing music allows to limit the proposal and, especially, it favours the accomplishment of an important didactic route, thanks to the characteristics and connotations that brings that music. The versatility of these audio-visuals and their relevance for a meaningful learning is confirmed by proposing examples that include both concert music (Mozart) and popular urban music (Led Zeppelin). Finally, the pre-existing music allows alternative didactic routes and interesting transversal learning options.

Keywords: Didactics of music; superhero movies; didactic through the audio-visual; Marvel movies; concert music; rock music. 
VICENTE GALBIS LÓPEZ

¿MOZART ERA UN MUTANTE? PROPUESTAS DIDÁCTICAS SOBRE LA MÚSICA

PREEXISTENTE EN EL CINE DE SUPERHÉROES

\section{INTRODUCCIÓN}

El origen de este artículo se basa en dos líneas de investigación que el abajo firmante desarrolla desde hace tiempo: el uso de la música preexistente en el audiovisual y la utilización de los audiovisuales para la Didáctica de la Música. En relación con este último aspecto, hemos podido comprobar la gran potencia del audiovisual para el aprendizaje significativo de la música en diferentes niveles educativos y titulaciones. Como señala Flores (2007), el aprendizaje debe partir de la conexión con el alumnado y con las experiencias de ese alumnado en su vida cotidiana. En este sentido, los medios audiovisuales resultan de una gran relevancia (Montoya, 2013).

Ello justifica la elección del cine de superhéroes como objeto de estudio, puesto que proporciona un resorte significativo evidente, es decir, un elemento que conecta de forma clara con los discentes. Desde el año 2000 se está viviendo un progresivo crecimiento de este «casi género cinematográfico», con una serie de películas que han ido estrenándose de forma sistemática y con un éxito creciente. Por ello, se trata de audiovisuales conocidos por el alumnado de niveles como primaria, secundaria y educación superior. De hecho, los discentes del último nivel citado han ido creciendo con el éxito progresivo de estas películas. Lo anterior justifica que esta propuesta se dirija de forma especial a estos últimos estudiantes, aunque podría funcionar en secundaria y bachillerato con las adaptaciones correspondientes.

El hecho anterior y la necesidad de acotar la propuesta nos ha llevado a centrar el objeto de estudio en películas basadas en personajes de la editorial Marvel. En las dos últimas décadas, este corpus cinematográfico muestra el éxito obtenido al trasladar el concepto de «universo compartido» originado en sus cómics. La existencia de unos personajes (interpretados por los mismos actores y actrices) y unas tramas que permanecen y, a la vez, evolucionan, crean en la audiencia (es decir, en nuestro potencial alumnado) una fidelización que está alimentada por una creciente expectación. Aspecto que, a su vez, se basa en unas tramas que van pasando de una película a otra, trasladando al cine el concepto de «continuidad», también una seña de identidad de los cómics de Marvel.

Por si todo ello fuera poco, la conexión con nuestro potencial alumnado se incrementa con otros factores como la presencia creciente en nuestro ámbito del medio en el que nacieron estos personajes: el cómic (véase el creciente espacio que ocupan en las grandes superficies comerciales). Ello supone una interesante retroalimentación, puesto que elementos de la versión cinematográfica exitosa de un personaje o un grupo pasan con frecuencia al mundo del cómic. Además, se debe añadir la expansión a otros medios audiovisuales como la televisión (en sus diversas modalidades de emisión) y, como elemento aglutinador, la existencia de un enorme merchandasing que expande todos estos productos. Todo ello asegura 
VICENTE GALBIS LÓPEZ

¿MOZART ERA UN MUTANTE? PROPUESTAS DIDÁCTICAS SOBRE LA MÚSICA PREEXISTENTE EN EL CINE DE SUPERHÉROES

la presencia del universo superheroico en el entorno cotidiano de nuestro alumnado. Jordi Costa (2018) añade una comparación con otros audiovisuales de gran auge en la actualidad: las series de televisión. El concepto del UCM (Universo Cinemático Marvel), con sus sucesivas entregas, plantea un paralelismo con los episodios de las temporadas televisivas. En este sentido, destaca que la fidelización con el espectador también se podría comparar con la que se producía en los antiguos seriales cinematográficos.

Por otro lado, la elección de un trabajo didáctico sobre música preexistente en estas películas se justifica, en primer lugar, por la posibilidad de ofrecer otros recorridos didácticos más allá del aprendizaje musical, tal y como luego se explicará. Asimismo, el uso de la música preexistente destaca frente a la música original que, habitualmente, suele predominar en las bandas sonoras de estos audiovisuales y que resulta, en general, más uniforme desde el punto de vista estilístico. Por último, la existencia de variados ejemplos de música preexistente permite una acción didáctica atractiva para trabajar, por ejemplo, la unión con la historia de la música a través del aprendizaje significativo. Los aspectos anteriores justifican aún más la elección de la educación superior como el ámbito más interesante para el desarrollo de las propuestas que a continuación se ofrecen. En este sentido, se han podido implementar en dos titulaciones de tipo universitario: en la materia de Historia de la Música en el Grado de Historia del Arte y en el Máster Universitario en Profesor/a de Educación Secundaria, pertenecientes en ambos casos a la Universitat de València. En la primera titulación se trabajaron las propuestas descritas y en la segunda se comentaron las posibilidades didácticas de las actividades planteadas con los discentes del Máster.

En cuanto a los criterios de selección de los audiovisuales que se van a presentar, tenemos, en primer lugar, dos películas de cronología distinta, pero que representan de forma clara el inicio del auge, por un lado, y la presente etapa de culminación de este tipo de filmes. A su vez, se trata de unos audiovisuales representativos de las dos grandes productoras que han impulsado las películas basadas en los personajes de Marvel. Por un lado, la Fox, auténtica protagonista, junto con Sony de los orígenes de esta expansión a principios de siglo y, por otro lado, Marvel Studios, responsable del UCM desde hace una década y artífice de la eclosión de estos filmes. Otro factor que une a estas películas diferentes y les confiere un atractivo especial para el análisis, es que el uso de la música preexistente está diseñado, en gran parte, por el principal responsable artístico, es decir, el director.

Para concluir con las razones que justifican esta elección de audiovisuales se cita el contraste que se establece entre las músicas preexistentes y el resto de la banda sonora musical de las películas a las que pertenecen, lo que intensifica la sensación de sorpresa al visualizar las escenas en las que son utilizadas. Los audiovisuales propuestos en el artículo se pueden localizar fácilmente en la plataforma YouTube. 
VICENTE GALBIS LÓPEZ

¿MOZART ERA UN MUTANTE? PROPUESTAS DIDÁCTICAS SOBRE LA MÚSICA

PREEXISTENTE EN EL CINE DE SUPERHÉROES

\section{$X-M E N$ 2: SECUENCIA INICIAL}

La primera de las dos películas propuestas es $X$-Men 2 (X2) estrenada en 2003 como secuela de la exitosa en cuanto a crítica y público $X$-Men, tres años anterior. Los primeros años del siglo XXI suponen el inicio de esta etapa de auge $\mathrm{y}$ ofrecen un contexto favorable a un filme como $X$-Men 2, que también tuvo muy buena aceptación al avanzar un paso más en la traslación del elemento diferenciador del grupo homónimo de la Marvel: la caracterización psicológica de los mutantes. Se trata de unos seres diferentes debido a su genética, que les otorga unos superpoderes que, de forma significativa, causan el miedo en una sociedad a la que intentan proteger. Lo que les lleva, en muchas ocasiones, a la condición de marginados sociales (Barnés, 2015).

$X$-Men 2 se basa libremente en la novela gráfica Dios mata, el hombre mata (Claremont; Anderson, reed. 2018), publicada en 1982 por el guionista Chris Claremont y el dibujante Brent Eric Anderson. Esta obra lleva la oposición entre mutantes y «homo sapiens» a un escalón superior, es decir, a la guerra. De hecho, mientras que en la primera película de la saga se mostraba un enfrentamiento entre los mutantes «buenos» comandados por Charles Xavier y los mutantes «malos» (es decir, que preconizaban la lucha contra la humanidad) liderados por Magneto; en $X$ Men 2 los personajes negativos son directamente unos militares que quieren exterminar a todos los mutantes (Casas, 2011).

Esta sinopsis inicial resulta necesaria para entender el primer audiovisual que se propone que, a su vez, constituye la primera escena de $X-M e n 2$. Una secuencia que todavía sorprende por su propuesta visual, la música preexistente utilizada y por el tratamiento del sonido. Esto se explica, entre otras razones, porque el protagonista de la escena se define por su llamativo aspecto físico (es una especie de elfo demoníaco de color azul) y por lo sonoro, ya que, además de su extraordinaria agilidad, tiene el superpoder del teletransporte, es decir, desaparecer en un sitio y aparecer en otro. Cada una de estas apariciones-desapariciones viene acompañada de un humo azul y, sobre todo, por un peculiar sonido, una especie de bamf (AA. VV., 2007).

El personaje se llama Rondador Nocturno (Nightcrawler en su denominación original) $y$, en esta escena, aparece inicialmente camuflado como un turista que visita la Casa Blanca. A continuación, se descubre y realiza un espectacular ataque por las dependencias del ala oeste, enfrentándose con diversos componentes del Servicio Secreto hasta llegar al Despacho Oval con el objetivo de matar al Presidente de los Estados Unidos

En un primer visionado ya destaca algo que resulta atractivo para el alumnado: pese a los quince años transcurridos, esta escena es todo un prodigio en cuanto al aspecto visual (De Prada; Rodríguez, 2012). Prácticamente encontramos todo el repertorio de movimientos de cámara (travellings, panorámica), colocación 
de cámara (picados, contrapicados), toda la escala de planos, acción con efectos físicos (cables), digitales (el bamf), ópticos (cámara lenta, pantalla verde)... y todo ello combinado con un montaje apabullante... cuyo responsable, John Ottman, es también el autor de la música original de la película. Que el montador sea también el compositor explica la gran aportación audiovisual de esta propuesta. Además, Ottman es uno de los componentes fijos en el equipo de Singer hasta la actualidad, lo que denota el grado de colaboración con el director a la hora de preparar la secuencia.

Captada la atención del alumnado, se puede efectuar un primer nivel de trabajo didáctico con las características musicales, sin necesidad todavía de hablar de autorías. Teniendo en cuenta la prodigiosa filmación de Singer, las características musicales del fragmento resultan totalmente adecuadas a las imágenes del ataque de Rondador Nocturno (Alan Cumming): tempo rápido, dinámica fuerte, predominio en el timbre orquestal de viento metal y percusión y un uso insistente de la textura homofónica en el coro. Elementos que se pueden confirmar en una audición musical, independiente de la escena. En definitiva, la selección de la pieza (convenientemente arreglada) se adecua a la trepidante acción.

Un segundo nivel de trabajo didáctico ya nos llevaría a la autoría: se trata del «Dies Irae» del Requiem de Mozart. Precisamente, el concepto de Requiem como «misa de difuntos» se puede relacionar con el peligro inminente de un asesinato. El espectador que conozca previamente la pieza musical puede otorgarle un significado que complementa las características musicales reseñadas; es decir, la pieza de Mozart cumple una «función intelectual», siguiendo la terminología de Jaume Radigales (2005). Aún más interesante resulta el trabajo didáctico sobre el metatexto, es decir, la letra que transmite el «Dies Irae», que son las dos primeras estrofas de la Sequentia. La idea principal se transmite en la traducción del mismo título: el día de la ira. La furia que muestra Rondador Nocturno en su implacable ataque, en el que deja diezmado a todo el personal del Servicio Secreto.

Profundizando aún más, en un tercer nivel de trabajo didáctico se puede desarrollar un elemento que se clarifica a lo largo de la película. Rondador realiza el ataque manipulado mentalmente por William Stryker (Brian Cox), el militar que quiere acabar con los mutantes. Sin embargo, a lo largo del filme se comprueba algo que ya saben los aficionados a los cómics de Marvel: en realidad, Rondador es la bondad personificada. De hecho, en la película no es utilizado como fuerza de ataque: se dedica a defender y salvar a los principales personajes. En este sentido, se podría comentar la relación con la música de Mozart: en los cómics y en la película Rondador es un devoto católico; por ejemplo, le vemos rezar antes de entrar en acción en las peligrosas operaciones de los X Men (De Prada; Rodríguez, 2012). En esta dirección, la música utilizada es una pieza religiosa... con un texto que habla de la ira. 
Volviendo a la escena propuesta, se podría enriquecer el tratamiento didáctico insistiendo en una breve sección en la que destaca la maestría en el uso dramático de los efectos de sonido, combinados con música original y con la pieza musical preexistente. Sucede cuando Singer crea una gran tensión al enfocar la acción desde el interior del despacho oval, con un aterrorizado Presidente y unos desconcertados componentes del Servicio Secreto. El director crea esa tensión al eliminar toda referencia visual de Rondador Nocturno. Sin embargo, lo sentimos al otro lado de la puerta y en el techo del Despacho Oval gracias a los efectos de sonido. A ello se le añade una discreta música original de John Ottman, que incide en esa tensión. Todo esto concluye con la entrada apabullante de Rondador Nocturno en el despacho y, de forma simultánea, con el regreso del «Dies Irae» mozartiano.

Otro itinerario didáctico que podría partir de lo anterior es un trabajo transversal sobre valores. Como ya se ha dicho, el gran tema de los cómics de los $\mathrm{X}-\mathrm{Men}$ es la intolerancia con lo diferente: estos personajes son rechazados por la gente a la que pretenden ayudar, debido a que son distintos e esas personas (Casas, 2011). Resulta evidente (y se puede trabajar en el aula) la metáfora social aplicada a otras razas, culturas, orientaciones sexuales, etc. Aún más, se pueden elaborar unas actividades sobre la importancia concedida a la apariencia física, en la que el miedo a lo diferente resulta aún más claro. Así, el físico demoníaco de Rondador contrasta con su personalidad bondadosa y su generosidad.

En esta dirección, también se puede elaborar con el alumnado una lectura histórico-social. La película se estrena solo tres años después del ataque a las Torres Gemelas en Nueva York y toda la paranoia de miedo al diferente que generó y que, en parte, todavía se vive en la actualidad. Por último, en la primera película de la saga se indica de forma clara que el odio de Magneto hacia el homo sapiens nace de su experiencia como niño judío (minoría marginada) en un campo de exterminio de los nazis, lugar en el que mueren sus padres. Toda esta lectura sobre la intolerancia ya aparecía, de una forma aún más clara, en el cómic sobre el que se basa la película: la novela gráfica Dios mata, el hombre mata. De hecho, en la parte final del cómic resulta fundamental el personaje de Rondador Nocturno, al que Chris Claremont y Brent Anderson (2018 reed.) convierten en símbolo máximo de la intolerancia hacia lo diferente. Algo que se retoma, como se ha comentado anteriormente, en $X$-Men 2.

En este punto de la identificación entre música y personaje, se pueden hacer unas actividades sobre otras secuencias de $X$-Men 2 en las que aparece, de forma diegética, la música de Mozart. De forma significativa, se asocian a Magneto, uno de los mutantes más poderosos e inteligentes. Así, en la celda de plástico en la que aparece confinado en el primer tercio de la película, el personaje interpretado por Ian McKellen escucha un fragmento de la «Romanza», el segundo movimiento de la Pequeña Serenata Nocturna, K. 525 y en otra escena está oyendo el inicio de la 
VICENTE GALBIS LÓPEZ

¿MOZART ERA UN MUTANTE? PROPUESTAS DIDÁCTICAS SOBRE LA MÚSICA

PREEXISTENTE EN EL CINE DE SUPERHÉROES

famosa Sonata para piano N 16, K 545. Llama la atención que Singer ha utilizado piezas de Mozart en otras películas para asociarlas con personajes de inteligencia superior y que, además, son malvados. Este sería el caso del melómano Lex Luthor que aparece en Superman Returns, solo tres años posterior a $X$-Men 2. El trabajo didáctico con el alumnado se podría basar en argumentar los criterios de selección de las dos piezas citadas e, incluso, comparar su uso con el que el director efectúa en la película protagonizada por el héroe nacido en Krypton.

\section{$X-M E N$ 2: TRÁILER DE CINE 1}

El segundo audiovisual que se propone relacionado con $X$-Men 2 no es una escena de la película, se trata de uno de los tráilers previos al estreno de la película, en concreto el primer tráiler que se lanzó para los cines. Resulta un audiovisual muy significativo en el contexto de este artículo, ya que está basado en una música de concierto preexistente y, además, no se trata del «Dies Irae» mozartiano. Por otra parte, al ver la película completa, la música utilizada en este tráiler cobró todo su sentido, aparte de la funcionalidad inmediata de su acompañamiento a las imágenes del propio audiovisual. Asimismo, este formato constituye un tipo de audiovisual muy atractivo para el trabajo didáctico ya que el alumnado está acostumbrado a seguir en plataformas como YouTube los tráilers lanzados por las productoras con los que, precisamente, crean esa expectativa que se comentaba anteriormente. Pasando al análisis concreto, desconozco si Bryan Singer es el responsable directo de la sonorización con la música preexistente, pero creo que es un dato secundario, resulta un producto muy atractivo y complementario de la escena inicial de la película.

En un primer nivel, se pueden trabajar las características musicales del tráiler, que se corresponden con las dos partes del audiovisual. La primera parte está marcada por una calma tensa que recupera, además, la escena final de la primera película de la saga: la partida de ajedrez en la cárcel de plástico de Magneto, planteada entre este último y el profesor Xavier. La segunda parte del tráiler comienza con la entrada en escena de Lobezno, el montaje espectacular con toda la acción, la aparición breve de los personajes principales, etc. La sincronización resulta evidente en el final, cuando los tres últimos golpes de la orquesta coinciden con tres datos fundamentales que aporta el tráiler: día y mes de estreno y el carácter de mundial de dicha presentación. Por último, el espectacular acorde final acompaña al logo de la película, tras la aparición de un Lobezno desatado.

En un segundo nivel de trabajo didáctico se puede comentar la autoría y su relación con las características musicales. Se trata de un arreglo efectuado con varios fragmentos de «Marte, el portador de la guerra», perteneciente a la suite orquestal Los Planetas, de Gustav Holst. También podríamos jugar didácticamente con el 
propio título de la pieza (la aparición de timbres asociados a la guerra) y, sobre todo, con la adecuación argumental a la película que presenta el tráiler. Se debe recordar que $X$-Men 2 narra la guerra de unos humanos contra los mutantes en la que, además, los villanos son unos militares. El ostinato rítmico de tipo militar (se trata de Marte, el dios de la guerra) comienza marcado por la cuerda, utilizando la técnica del col.legno, acompañando esa tensión inicial de la partida de ajedrez.

A continuación, el componente rítmico se incrementa al aparecer marcado por toda la orquesta, lo que coincide, de forma coherente, con las imágenes de acción. Los golpes de orquesta y el impactante acorde final del tráiler también coinciden con el final de «Marte, el portador de la guerra». Por tanto, se trata de un arreglo de la música preexistente de Holst adaptado a las imágenes del tráiler de una forma muy clara, lo que permite un aprendizaje eficiente. Este itinerario didáctico se enriquece con el metatexto, no de la música, que es orquestal, sino de lo que se transmite en el tráiler: en la parte conclusiva del audiovisual la música deja de sonar para que se escuche perfectamente la frase de Magneto: the war is began. En definitiva, un audiovisual que habla de la guerra humanos-mutantes, acompañado por una música relacionada, de forma coherente, con lo bélico.

Avanzando en el proceso de aprendizaje, el alumnado puede, además, reconocer sin problema una «sonoridad superheroica», basada en unos rasgos que les resultarán familiares, como la abundante orquestación, el predominio del viento metal, la presencia del ostinato rítmico, etc. Estos rasgos pueden ser comparados con fragmentos muy similares de John Williams en la película Star Wars: Episodio IV - Una nueva esperanza o, profundizando un poco más, estableciendo una génesis de este «sonido heroico» al comparar la música de Williams con las bandas sonoras que Erich Wolfgang Korngold compuso para las películas de aventuras de Warner Brothers que protagonizó Errol Flynn (El capitán Blood, Robin de los Bosques o El balcón del mar), tal y como señalan especialistas como Kathryn Kalinak (1992). Además del aprendizaje musical, el alumnado puede comprobar de esta forma las influencias entre compositores y reconocer en «Marte, el portador de la guerra» de Gustav Holst, una pieza de música «superheroica» compuesta varios años antes de que nacieran los tebeos de superhéroes.

Por último, el tráiler tiene otro elemento que intensifica la conexión con el alumnado: la aparición de unos actores que se identifican con la franquicia cinematográfica de los mutantes hasta hace unos pocos años. Así, a lo largo de su breve extensión temporal vemos en el tráiler a los mutantes más jóvenes (en los cómics originales, los X-Men eran muy jóvenes, casi adolescentes) lo que puede utilizarse para la identificación con el alumnado. A su vez, en el tráiler aparecen los actores adultos que han desempeñado estos papeles durante dos décadas y que, en casos como el de Hugh Jackman (Lobezno), son los que les han dado a conocer al gran público. Otro elemento de conexión con el alumnado es que los 
VICENTE GALBIS LÓPEZ

¿MOZART ERA UN MUTANTE? PROPUESTAS DIDÁCTICAS SOBRE LA MÚSICA

PREEXISTENTE EN EL CINE DE SUPERHÉROES

discentes pueden reconocer actores de la franquicia mutante que han aparecido en otras sagas cinematográficas de mucho éxito. Así, Ian McKellen interpreta a Magneto, pero también es Gandalf en El Señor de los Anillos y Patrick Stewart es el profesor Xavier, a la vez que interpreta al capitán Picard en el universo de Star Trek.

\section{THOR RAGNAROK - TEASER TRÁILER}

Con la segunda película propuesta se realiza un salto de catorce años, puesto que se trata de un filme de 2017, mucho más reciente. En este caso, se realiza un procedimiento contrario al de $X$ Men 2, primero se proponen unas actividades didácticas sobre el tráiler y luego se trabajará una escena de la película.

Thor: Ragnarok constituye la tercera película de la franquicia basada en el Dios del Trueno de los cómics Marvel y fue dirigida por Taika Waititi. En este filme, Thor (Chris Hemsworth) se enfrenta con Hela (Cate Blanchett), la diosa de la Muerte, que pretende conquistar Asgard y acabar con los dioses. Precisamente, ese es el concepto del Ragnarok, el destino final de los dioses. Los aspectos comentados anteriormente constituyen los elementos principales que aparecen en el Teaser Tráiler propuesto.

El trabajo sobre la música preexistente se realiza sobre una música popular urbana que es la pieza que predomina en la banda sonora musical del tráiler. Se trata de una canción de Led Zeppelin titulada «Inmigrant Song», compuesta por Jimmy Page y Robert Plant. Fue publicada por el mítico grupo en 1970, dentro del disco Led Zeppelin III. Una vez captada la atención del alumnado por la popularidad y vigencia de los personajes y, además, por la relativa actualidad de la película, comenzaría el trabajo didáctico comentando las características musicales de la canción de Led Zeppelin y su adecuación a lo que aparece en el tráiler. Además de la dinámica fuerte, el timbre vocal tan característico del inicio, el tempo, etc. el famoso riff inicial de guitarra (Popoff, 2019) resulta clave en el inicio y en el final del tráiler. Su carácter ostinato (estableciendo las pertinentes diferencias estilísticas se podría comparar con el de «Marte, el portador de la guerra» de Holst) refleja las escenas de acción que jalonan la mayoría del tráiler. El alumnado puede comprobar que «Inmigrant Song» solo desaparece para enfatizar la espectacular entrada de un personaje que no necesita música: el increíble Hulk (Mark Ruffalo). Tras su aparatosa entrada y las breves palabras del Dios del Trueno, se vuelve a escuchar a Led Zeppelin, con el regreso al famoso riff como conclusión del tráiler.

En un segundo paso de la propuesta didáctica podría trabajarse la letra de la canción, ya que estamos ante un metatexto que presenta una sorprendente adecuación al argumento de la película, décadas después de su lanzamiento en 
disco. A continuación, solo se incluye el texto de lo que suena en el tráiler, que es prácticamente la primera mitad de la pieza:
«Ah, ah,
We come from the land of the ice and snow
From the midnight sun
Where the hot springs blow
Hammer of the gods
Will drive our ships
To new lands
To fight the bordes, singing and crying
Valhalla, I am coming!
On we sweep with threshing oar,
Our only goal will be the western shore».

Resultan muy interesantes de cara al tráiler y, por extensión, a la película, las partes subrayadas del texto. Así, se observan las referencias a los vikingos («venimos de la tierra del hielo y la nieve») ya que los dioses nórdicos que aparecen en la película (Odín, Thor, Loki) eran las deidades de este pueblo. También hay que citar la referencia al «martillo de los dioses» (es decir, Mjolnir, el martillo encantado de Thor). De hecho, esos gritos tan peculiares del inicio representarían los gritos de ataque de los vikingos («luchar contra las hordas»). Dicha referencia puede dar lugar a trabajar otras canciones de Led Zeppelin con ciertos paralelismos en cuanto al argumento, ya que el grupo tuvo un especial interés en crear piezas como «Stairway to Heaven», basada en mitos y leyendas celtas, con referencias a El Señor de los Anillos, etc. (Popoff, 2019).

En este sentido, resulta significativo que la inclusión de esta pieza fuera una exigencia del director para implicarse en el proyecto (Gimeno, 2017). Esa relevancia se demuestra en que «Inmigrant Song» no solo es la música del tráiler, sino que aparece en dos escenas fundamentales y épicas de la película: la secuencia del inicio (la lucha de Thor con Surtur, el demonio de fuego) y la batalla final de todos los personajes contra Hela y su ejército. En este artículo se propone la segunda, debido a la aparición de más personajes y a una mayor opción para otros recorridos didácticos. Asimismo, la inclusión de música rock preexistente resulta adecuada a una película que destaca por una apuesta visual cercana al mundo de la cultura popular y que rompe con la solemnidad adoptada en las dos películas anteriores relacionadas con el Dios del Trueno (Ocaña, 2017). Esta diversidad en el tratamiento visual y argumental, se complementa con la ecléctica banda sonora original de Mark Mothersbaugh, que va de lo sinfónico al «sonido discoteca», de forma coherente con las imágenes que va proponiendo Taika Waititi. 
VICENTE GALBIS LÓPEZ

¿MOZART ERA UN MUTANTE? PROPUESTAS DIDÁCTICAS SOBRE LA MÚSICA

PREEXISTENTE EN EL CINE DE SUPERHÉROES

\section{THOR RAGNAROK: LA ESCENA FINAL}

En realidad, habría que concretar que la propuesta se limita a la primera parte de la gran escena de acción con la que prácticamente concluye la película, dejando aparte el epílogo. Esta sección comienza con el enfrentamiento final de Thor y Hela, en el que el Dios del Trueno recupera sus poderes y, por primera vez en todo el filme, consigue superar a la Diosa de la Muerte. A continuación, Thor pasa a ayudar a sus aliados en la lucha contra el ejército de Hela. En esta parte de la secuencia vemos en acción a Loki (Tom Hiddleston), Valquiria (Tessa Thompson) y Heimdall (Idris Elba), entre otros personajes importantes. A ellos se añade Hulk para comenzar a inclinar la balanza hacia el lado de los dioses. Ello permitirá a los asgardianos iniciar la subida a la nave que los llevará a otro hogar, lejos de un Asgard dominado por Hela.

El trabajo didáctico comenzaría con las características musicales adecuadas para la batalla ya comentadas, pero aquí se añade una presencia del metatexto aún más relacionada con lo que se aprecia en las imágenes. Por ejemplo, se observa la nave espacial que servirá para transportar a los dioses asgardianos, guiados por Thor, a una nueva tierra tras la destrucción de Asgard en el Ragnarok. Todo ello mientras que el grupo Led Zeppelin canta este texto tan significativo:

«Hammer of the gods

Will drive our ships

To new lands».

Algo similar ocurre cuando se incorpora a la batalla sobre el puente Bifrost el personaje de Valquiria: se escucha la referencia al Valhalla, el lugar al que llevaban a los héroes caídos en combate estas mujeres guerreras llamadas Valquirias. A continuación, se incluye la letra que acompaña dicha incorporación:

«To fight the hordes, singing and crying

Valhalla, I am coming!».

Pero, además de las referencias anteriores, en este breve fragmento aparecen una serie de personajes y elementos que nos permiten relacionar didácticamente la película y la canción de Led Zeppelin con un tema que suele resultar un poco denso para el alumnado: la aportación de Richard Wagner a la historia de la música occidental. En la tetralogía de El Anillo del Nibelungo aparecen una serie de personajes, especialmente dioses, pero no solo ellos, cuyos equivalentes en la mitología nórdica vemos en esta breve escena de la película. De hecho, es bien sabido que una de las fuentes de Wagner como libretista de la tetralogía fue la mitología nórdica. 
Siguiendo la pauta de la escena, tenemos a Thor que en El oro del Rin es Donner, el Dios del Trueno. En esa misma pieza de Wagner encontramos a Loge, que en la mitología nórdica es Loki. Si dejamos aparte a los dioses, en la escena aparece Valquiria, cuyo nombre propio no se cita en la película pero que en los cómics sí que aparece: Brunhilde. Es decir, uno de los personajes femeninos de mayor importancia en El Anillo del Nibelungo. Podemos jugar no solo con personajes, la batalla se desarrolla sobre el puente Bifrost, que en la Tetralogía es el puente del arco iris, etc. Este juego de comparaciones se podría ampliar a otros personajes que no aparecen en la escena, pero sí en la película. Por ejemplo, Odín, el padre de los Dioses, es Wotan en la Tetralogía, o el concepto mismo de Ragnarok se podría extrapolar con algunas matizaciones al que se transmite en El Ocaso de los Dioses, la última jornada de El Anillo del Nibelungo.

Este recorrido didáctico que intenta conectar a nuestro alumnado con Wagner a través de la película y, no lo olvidemos, a través de Led Zeppelin, tiene aún otro punto de atractivo para los discentes. Se trata, precisamente, que podemos relacionar todo ello con la fuente, es decir, con los cómics. Precisamente, Marvel presenta una «mitología» sobre la mitología nórdica. Lo que hacen Stan Lee, Larry Lieber y Jack Kirby, creadores del cómic dedicado a Thor en 1962, es adaptar a sus intereses (cambiando elementos y añadiendo personajes nuevos) la mitología ya existente (González, 2016). Es decir, su tarea creativa fue, con todas las diferencias pertinentes, paralela a la de Wagner. Ese refuerzo de los cómics puede ayudarnos en este recorrido didáctico que, no se debe olvidar, nace de la película. En este punto, cabe citar que, gracias a estos tebeos de Lee, Lieber y Kirby, muchas personas se interesaron por la mitología nórdica. Este sería el caso del prestigioso escritor y guionista Neil Gaiman, un interés que le llevó escribir su libro Mitos nórdicos (Gaiman, 2017).

Otro itinerario didáctico totalmente distinto sería partir de la utilización de la canción «Inmigrant Song» en el cine. Al estudiar esta pieza constatamos su aparición en dos filmes bastante conocidos que nos permiten, además, motivar al alumnado de otros niveles educativos. El primero es School of Rock (2003), la recordada película de Richard Linklater protagonizada por Jack Black en la que la música rock y, precisamente, un grupo de alumnos de primaria llevan, junto a Black, el peso del filme. La otra opción propuesta sería Shrek 3 (2007), la tercera película de la conocida saga de animación que ya ha sido objeto de una propuesta didáctico-musical (Montoya, 2012). Se trata de películas muy diferentes entre sí, pero en las que el uso de «Inmigrant Song» está muy justificado de acuerdo con el contexto argumental. A su vez, cada una de ellas nos llevaría a otro itinerario didáctico que, además, podría compararse con la utilización de la pieza en Thor: Ragnarok. 
VICENTE GALBIS LÓPEZ

¿MOZART ERA UN MUTANTE? PROPUESTAS DIDÁCTICAS SOBRE LA MÚSICA PREEXISTENTE EN EL CINE DE SUPERHÉROES

Volviendo al nivel de educación superior (que es el que se dirige este artículo), el uso de «Inmigrant Song»en Thor: Ragnarok podría conducir a otra opción didáctica: la comparación con la utilización de la música pop-rock que se efectúa en dos de las películas del Universo Cinemático Marvel. Es decir, la banda sonora musical que se propone en los dos volúmenes de Guardianes de la Galaxia, estrenados en 2014 y 2017, respectivamente. Sin descartar las posibles opciones didácticas sobre el abundante uso de la música pop y rock preexistente en esas dos películas, dicha utilización ofrece algunas desventajas respecto a la propuesta en Thor: Ragnarok. En muchas ocasiones, los fragmentos que aparecen en los dos volúmenes de Guardianes de la Galaxia son de una duración muy reducida $\mathrm{y}$, sobre todo, apenas existe ese contraste con el resto de la banda sonora musical, un aspecto que sí se observa en la tercera película protagonizada por el Dios del Trueno, lo que le da un mayor atractivo al juego didáctico.

La coda final de este artículo se relaciona con la pregunta planteada en el título: ¿Mozart era un mutante? En principio, parece evidente el tono jocoso de la interrogación, aunque de inmediato se puede relacionar con la asociación efectuada entre Mozart y Rondador nocturno en $X$-Men 2 y también con Magneto, tal y como se indicó. Sin embargo, esta pregunta daría lugar, además, a una posible aplicación didáctica que permite trabajar contenidos pertenecientes a la materia de Historia de la Música. Recordemos que, en el universo de X-Men, los mutantes se presentan, en general, como unas personas jóvenes que muestran unos poderes extraordinarios (Losada, 2007). Es bien sabido que Mozart creó unas 626 obras en treinta y cinco años de vida, unas piezas con una calidad y, sobre todo, un nivel de innovación extraordinario. Solo en 1791, su último año de vida, compuso $L a$ clemenza di Tito, el Concierto para clarinete, La Flauta Mágica y, especialmente, la mayor parte del Requiem, la obra que se escucha en $X$-Men 2. Se puede deducir fácilmente una aplicación didáctica y lúdica que incide en el espíritu de aprendizaje significativo que pretende transmitir este artículo.

\section{REFERENCIAS BIBLIOGRÁFICAS}

AA. VV. (2007). La Enciclopedia Marvel. La guía definitiva de los personajes del Universo Marvel. Madrid: Pearson Educación.

Barnés, H. (2015). X-Men 2 (2003). El héroe mata, el villano ama. Dirigido por..., 458, 44. Casas, Q. (2011). Películas clave del cine de superhéroes. Barcelona: Robinbook.

Claremont, C. y Anderson, E. (2018). La patrulla X: Dios mata, el hombre mata. Barcelona: Panini Comics.

Costa, J. (2018). Los superhéroes y la batalla por el placer, Fotogramas, 2096, 8.

De Prada, Í. y Rodríguez, S. G. (2012). El viaje del superhéroe: la historia secreta de Marvel en el cine. Palma de Mallorca: Dolmen Editorial. 
VICENTE GALBIS LÓPEZ

¿MOZART ERA UN MUTANTE? PROPUESTAS DIDÁCTICAS SOBRE LA MÚSICA PREEXISTENTE EN EL CINE DE SUPERHÉROES

Flores, S. (2007). Principales acercamientos al uso de la música popular actual en la Educación Secundaria. LEEME. Revista de la Lista Electrónica Europea de Música en la Educación, 19, 1-16.

Gaiman, N. (2017). Mitos nórdicos. Barcelona: Destino.

Gimeno, S. (2017). 'Thor: Ragnarok'. Led Zeppelin ayudó a Taika Waititi a conseguir el puesto de director. Sensacine. 20/10/2017. Recuperado de: http://www.sensacine. $\mathrm{com} /$ noticias/cine/noticia-18560951/

Gonzaléz, M. (2016). Dioses, Héroes y Superhéroes. Barcelona: Ma non troppo.

Kalinak, K. (1992). Settling the Score: Music and the Classical Hollywood Film. Madison: The University of Wisconsin Press.

Losada, M. (2007). Los primeros mutantes. En A. Guiral (Ed.), Del tebeo al Manga. Una historia de los cómics. 4. Marvel Comics: un universo en constante evolución. Barcelona: Panini Comics.

Montoya, J. C. (2013). Educación musical renovada: una película por filmar. Eufonía. Didáctica de la Música, 57, 91-98.

Montoya, J. C. (2012). ¿Por qué le gusta Shrek a mi papá? Comprensión y trabajo didáctico sobre los referentes sonoros en el cine infantil. En T. Fraile y E. Viñuela (Eds.), La música en el lenguaje audiovisual. Aproximaciones multidisciplinares a una comunicación mediática. Sevilla: Arcibel Editores.

Ocaña, J. (2017). Un refresco superheroico. El País. 27/10/2017 Recuperado de: https:// elpais.com/cultura/2017/10/26/actualidad/1508994816_520510.html

Popoff, M. (2019). Led Zeppelin. Todos los álbumes, todas las canciones. Barcelona: Blume. Radigales, J. (2005). Usos y abusos de la Música 'Clásica' en el cine. Estudio de casos. En M. Olarte (Ed.), La música en los medios audiovisuales. Salamanca: Plaza Universitaria. 
